\title{
BEHA VIOUR OF CEMENT MORTAR AND ENGINEERED CEMENTITIOUS COMPOSITES IN BRICK MASONRY
}

\author{
Mervin Sanjith $\mathbb{I P}^{\# 1}$, Sivaram $\mathbf{M}^{\# 2}$ \\ \#1 Address:VITUniversity,ChennaiCampus,India,Phone:+91-9500136110, \\ email Id:mervin.sanjith@gmail.com \\ \#2 Address:VITUniversity,ChennaiCampus,India,Phone no:+91-98940852506, \\ email Id:sivaash1997@gmail.com
}

\section{ABSTRACT}

This study is focused on the mechanical behavior of traditional cement mortar compared with Engineered Cementitious Composites(ECC).ECC is a fiber based cementitious composites with two different fibers that enhances both tensile and strain properties. This study investigates the effect of ECC with conventional cement mortar in brick masonry under monotonic load.The bond strength of traditional mortar and ECC with the brick masonry were also examined by triplet test.It is found that the bond strength of ECC is 33\% higher than the traditional mortar and the compressive strength of the brick masonry unit with ECC is $36 \%$ higher compared to normal mortar.The micro cracking behavior of ECC is also observed that leads to higher bond strength.It is also found that ECC in the masonry unit enhances superior behavior in terms of cracking,compressive strength and bond strength.

Key words:Engineered Cementitious Composites, Brick Masonry, Triplet test, Polypropylene fibre, Steel fibre, Bond strength.

\section{INTRODUCTION}

Engineered cementitious composites (ECC) is a special class of high tensile and ductility concrete designed based on micromechanics design principle resulting a tensile strain capacity of more than 3\%[1].ECC is less brittle compared to normal concrete but the ductility of ECC is several hundred times more than normal concrete or fiber reinforced concrete (FRC).ECC is a mortar based mix containing cement and fine aggregate incorporated with polypropylene and steel fibres.[1].

The fresh property of ECC totally depends upon the type and amount of fibres used and mixing methods.Since the fresh property has a high impact on the mechanical properties of the concrete structure, ECC has the same mixing procedure similar to conventional 
concrete[2].The fibers should be mixed after mixing cement, fine aggregates, water and superplasticizer. The method of distribution of fibers also increases the tensile ductility of the engineered cementitiouscomposites[3].

Bond strength is a measure of the ability of mortar in the masonry unit to remain bonded to resist the applied stress and movement, particularly in tension. It is one of the major properties of masonry, particularly in low-rise domestic and commercial buildings. Bond strength is a major parameter required for the development of sufficient tensile strength in the masonry unit to resist wind and earthquake forces and also other minor movement. Inadequate bond strength will lead to cracking in masonry construction[4].

It is well known that the main factors influencing the bond between the masonry units and mortar joints are: (1) the type of mortars (2) the type of masonry unit (3) workmanship and also there exists some studies on effects of curing methods on bond characteristics of masonry units[5].

The process of bond development takes place as soon as the fresh mortar is applied on to the masonry units. The subsequent setting of the cement compounds is carried out by the absorption of mortar fluids into the masonry unit and the complete filling of mortar fines to the mortar unit interface. The continued hydration over longer period of time would further increase the bond strength[6].

Segura et al.,[7] investigated the effect of masonry wall with brick and lime mortar under monotonic and cyclic loading. Tests have been conducted on two types of specimens, the first is stack bond masonry wall and the second is running bond masonry wall.The test shows similar results in terms of strength and deformability for both the samples.

As the strength of mortar and brick increase,the strength of masonry wall also increases [8].Konthensingha et al.,[9] examined bond and compressive strength of locally available bricks and normal cement mortar.The shear bond strength test is carried out by triplet test.The result show that the soaking time of brick has a good impact on bond and compressive strengths.It is also observed that the bricks and mortar with higher tensile bond strength gives higher shear bond strength.

Sarangapani et al.,[10] observed that there is an increase in bond strength by 4 times that of the plain brick mortar interface with the use of epoxy coating as enhancing material.The dry or saturated bricks resulted in poor bond strength due to moisture content of approximately $75 \%$ of the saturation value [11].The dry cured thin layered mortar specimen exhibits higher bond strength and Youngs modulus compared to wet cured specimens [12].The bond strength between brick and mortar is influenced by many factors such as types of mortar, surface characteristics, water absorptions of the brick, shape and size of frog and curing method [13][15].Based on the inference from the previous studies,this experimental investigation is focused on the study of strength of ECC and its effects on the masonry units. 


\section{EXPERIMENTAL PROGRAM}

\subsection{Materials}

Ordinary Portland Cement OPC 53 grade is used with the specific gravity of is 3.15.Manufactured or $M$ sand passing through 300 micron sieve is used as fine aggregate.Ordinary potable tap water was used for both mixing and curing.High range water reducing admixture is used to maintain good workability, $1 \%$ steel fibers and $1 \%$ polypropylene fibers are used.The normal mortar is prepared as per IS2250(1981) and the ECC mixture is prepared based on micromechanics design principle[2].

The properties of fibers and superplasticizer are given in Table 1 and Table 2 respectively.

Table1. Properties of Fibers

\begin{tabular}{|c|c|c|}
\hline \multirow[t]{2}{*}{ Properties } & \multicolumn{2}{|c|}{ Types of fibres } \\
\hline & Steel & Polypropylene \\
\hline Length(mm) & 26 & $10-15$ \\
\hline Diameter(mm) & 0.7 & $0.03-0.04$ \\
\hline Aspect ratio & 37.1 & $100-166$ \\
\hline Type & Hooked end & Monofilament \\
\hline Tensile strength(MPa) & 1000 & 551 \\
\hline Modulus of Elasticity(GPa) & 200 & 4 \\
\hline
\end{tabular}

Table2. Properties of Superplasticizer

\begin{tabular}{|l|l|}
\hline Type & Polycarboxlic \\
\hline Appearance & Yellowish viscous fluid \\
\hline $\mathrm{pH}$ & $\mathbf{8 . 5}$ \\
\hline Chloride & $\leq \mathbf{0 . 0 1}$ \\
\hline Sodium Sulphate & $\mathbf{\geq 0 . 2}$ \\
\hline
\end{tabular}




\subsection{Masonry Specimens:}

Two types of bricks were used fly ash brick and clay brick.Both the bricks were selected based on IS1077[16]. The size of fly ash brick is $(9 \times 7.5 \times 20 \mathrm{~cm})$ and that of clay brick is $(10 \times 7.5 \times$ $20.5 \mathrm{~cm}$ ). The masonry specimens are prepared for both compressive strength test and triplet test.The compressive strength test for masonry units are conducted as per BS EN772-1[17] and the triplet test is carried out based on EN1052-1[18].The specimens are prepared using both flyash and clay brick with normal mortar and ECC mixture.

\section{TEST PROCEDURE}

The compressive strength of mortar and ECC are tested at 7,14 and 28 days respectively.The bed joint plays a major role in increasing the strength of masonry wall.To test the compressive strength of normal and ECC mixture,cube size of 50mmwere cast and the mix design are given in Table3.

Table3. Mix Proportions

\begin{tabular}{|l|l|l|l|l|l|l|}
\hline Mix & Cement & M Sand & W/C & $\begin{array}{l}\text { Steel } \\
\text { fiber }\end{array}$ & $\begin{array}{l}\text { Polypropylene } \\
\text { fiber }\end{array}$ & Superplasticizer \\
\hline Mortar & 1 & 3 & 0.4 & - & - & - \\
\hline ECC & 1 & 0.6 & 0.36 & 0.01 & 0.01 & 0.005 \\
\hline
\end{tabular}

The properties of clay and flyash bricks were tested for compressive strength,water absorption and dry density[16].The triplet test were conducted for both normal and ECC mixtures as shown in Figure 1.Double layered masonry unit with clay and flyash brick is tested with traditional mortar and compared with ECC mix after 28 days of curing.

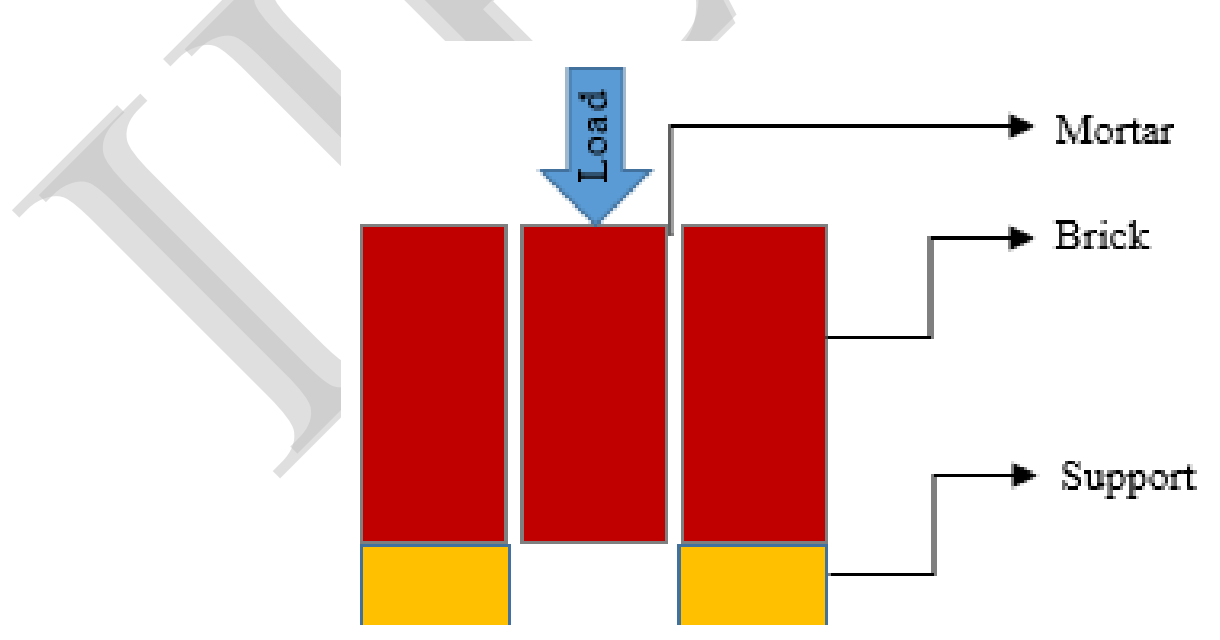

Fig 1:Triplet test setup 

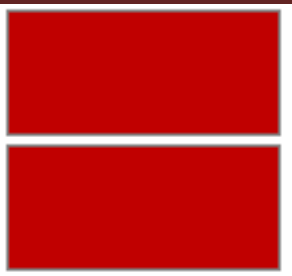

$420 \mathrm{~mm}$
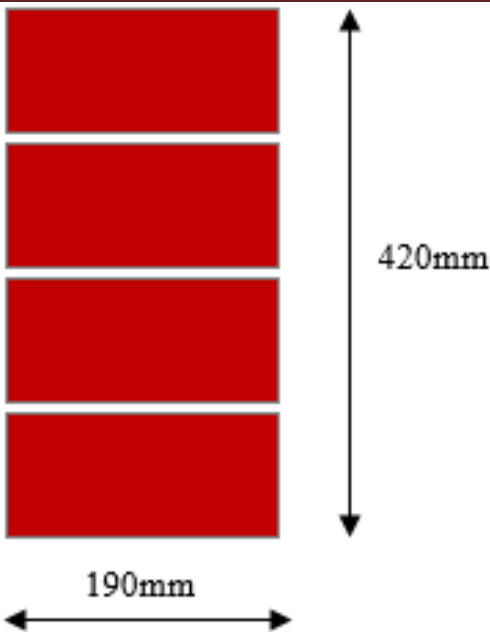

$190 \mathrm{~mm}$

Fig2: Specimen for compressive strength test

\section{RESULTS}

\subsection{Compressive strength of Mortar and ECC}

The compressive strength for traditional mortar and ECC were tested for 7,14 and 28 days respectively and the results are shown in Figure 4.

The compressive strength of traditional mortar were $23.4 \mathrm{MPa}$ and $51.4 \mathrm{MPa}$ at 7 and 28 days respectively whereas, ECC attained $40.56 \mathrm{MPa}$ and $79.2 \mathrm{MPa}$ at 7 and 28 days which was $55 \%$ more than the traditional mortar.This increase in strength is due to the incorporation of polypropylene and steel fibres which increases the load carrying capacity of the cement matrix.The micro crack behaviour is also observed due to the bridging of cement matrix by fibres. Thesamples after testing are shown in the Figure3.

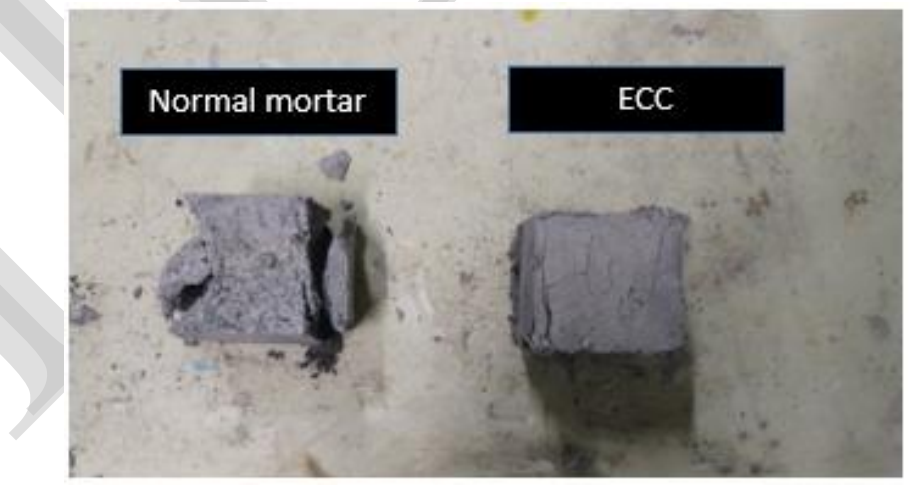

Fig3: Mortar specimen after compressive strength test

The research conducted by Bhaumik Merchant et al.[19] states that the percentage of fibre added to the mix has a large influence on the mechanical strength.If the addition of fibre exceeds $1 \%$ then the strength gradually decreases.The temperature also affects the strength of ECC.The compressive strength of ECC would decrease only if the temperature is raised above $200^{\circ} \mathrm{C}[20]$. 


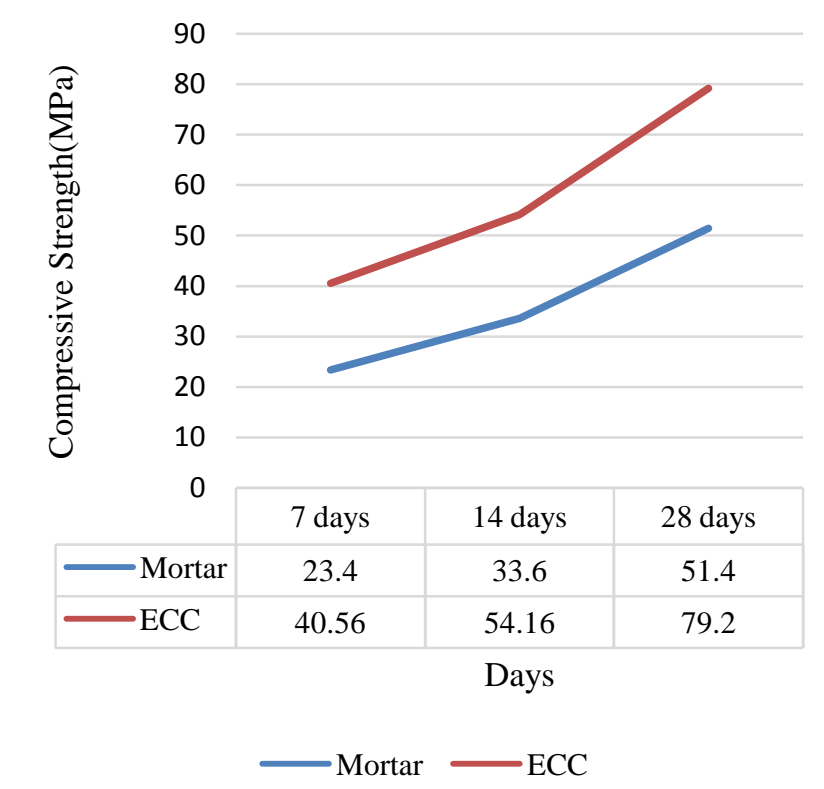

Fig4: Compressive strength of normal mortar and ECC

\subsection{Properties of brick}

The compressive strength of clay brick was 7.3 MPa whereas,flyash brick achieved a compressive strength of 10.3 MPa.The water absorption test were also conducted for both clay and flyash bricks in which the clay bricks absorbed $0.92 \%$ more water than the fly ash bricks. The properties of the bricks are mentioned in Table 4.

Table4. Properties of bricks

\begin{tabular}{|l|l|l|}
\hline \multirow{2}{*}{ Properties } & \multicolumn{2}{|l|}{ Type of Brick } \\
\cline { 2 - 3 } & Clay & Flyash \\
\hline Size $\left(\mathbf{c m}^{3}\right)$ & $10 \times 7.5 \times 20.5$ & $9 \times 7.5 \times 20$ \\
\hline Density $\left(\mathbf{g}^{\mathbf{3}} \mathbf{c m}^{\mathbf{3}}\right)$ & 1.67 & 2.02 \\
\hline Water absorption & $10 \%$ & $9.2 \%$ \\
\hline $\begin{array}{l}\text { Compressive Strength } \\
\text { (MPa) }\end{array}$ & 7.2 & 10.3 \\
\hline
\end{tabular}




\subsection{Bond Strength}

The test is carried out for both flyash and clay brick specimens for which normal mortar and ECC used as bed joints were compared.The bond strength of clay brick with mortar bed is 0.41 $\mathrm{MPa}$,whereas with ECC bed, the strength is found to be $0.6 \mathrm{MPa}$.Also the bond strength of flyash brick with mortar and ECC bed is $0.32 \mathrm{MPa}$ and $0.53 \mathrm{MPa}$ respectively.This increase in bond strength of ECC is due to its higher cement,fine aggregate and also the incorporation of polypropylene fibres that increased the shear capacity of bed joints.The mix proportions mentioned in AS3700[21] for the generic types of masonry units attained the implicit bond strength of 0.20 MPa.RonaldLumantarna et al.[14] studied the shear bond strengths of in-situ New Zealand unreinforced clay brick masonry constructed using lime mortar between the 1880s and 1940s. The results of the bond strength varied from 0.2 to $0.5 \mathrm{MPa}$ for different mixes of mortar from the above studies.Thus ECC obtained around 20\% increase in bond strength compared to other mortar mixes used in previous research.

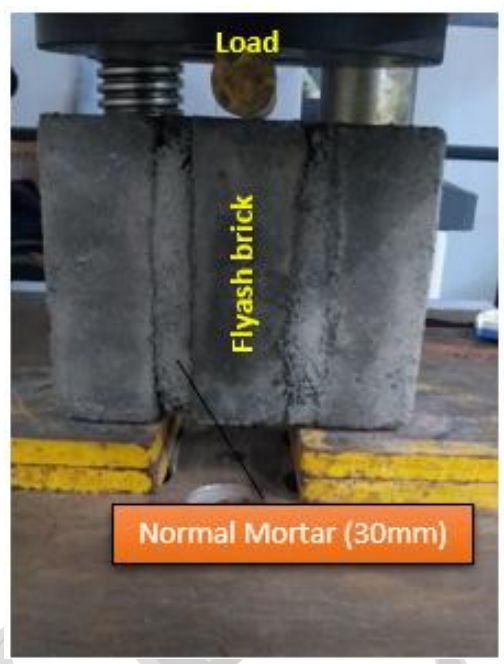

Fig5: Triplet test sample 1

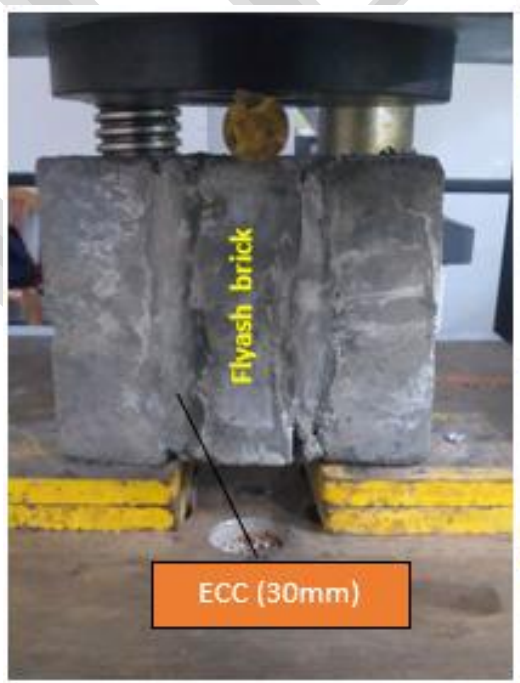

Fig7: Triplet test sample 3

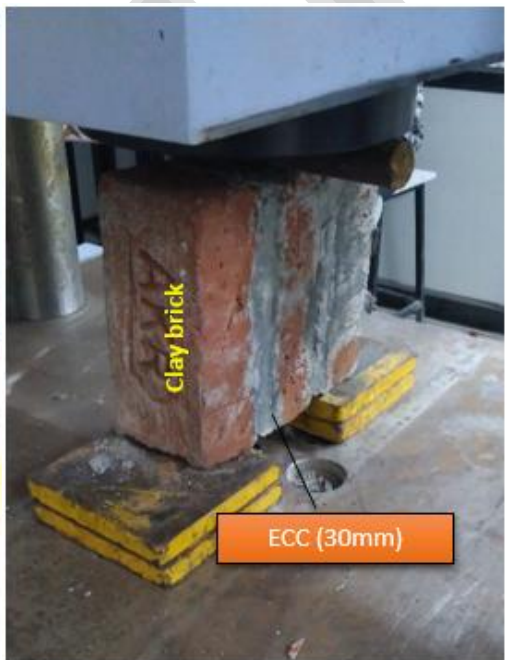

Fig6: Triplet test sample 2

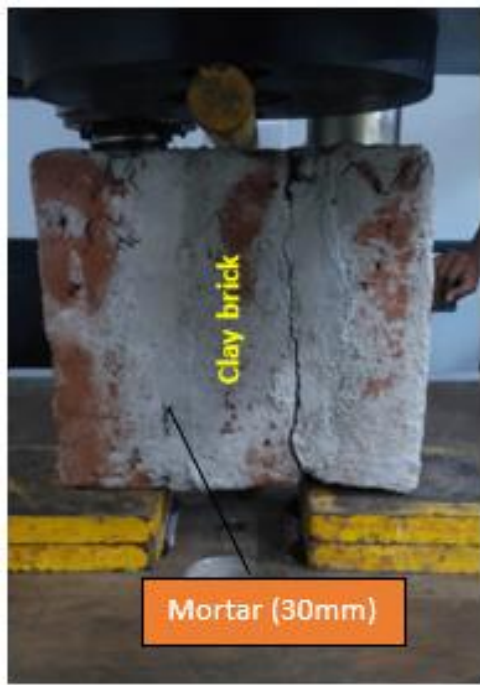

Fig8: Triplet test sample 4 


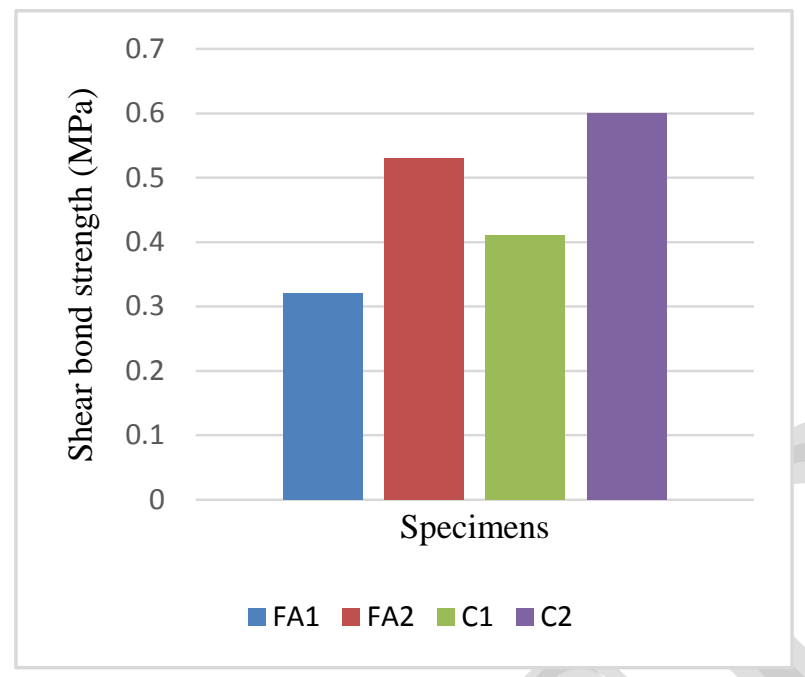

Fig9: Bond strength

Where,FA1-Flyash brick with normal mortar,FA2-Flyash brick with ECC,C1-Clay brick with normal mortar,C2-Clay brick with ECC.

\subsection{Compressive strength(Masonry Unit)}

The brick masonry unit is made using traditional mortar as well as ECC as bed joint for both clay and Flyash.The flyash brick masonry unit with mortar as bed joints attained a strength of 2.3 MPa whereas, with ECC bed joints it was found to be $3.92 \mathrm{MPa}$ at 28 days.Similarly the clay brick masonry with mortar bed achieved $2.1 \mathrm{MPa}$ whereas with ECC bed it was $2.9 \mathrm{MPa}$.It was found that the compressive strength achieved by prism with ECC bed is found to be slightly more when compared to the normal mortar bed. Gregoire[22] tested compressive strength on masonry units with different sizes and is observed that the strength is greater than $2 \mathrm{MPa}$ for all the samples.Similarly EN772-1[17] also states that the compressive strength varies for different area of application of load.Thus ECC on masonry units exhibit around 40\% to $90 \%$ increase in compressive strength compared to all other mixes from previous studies.

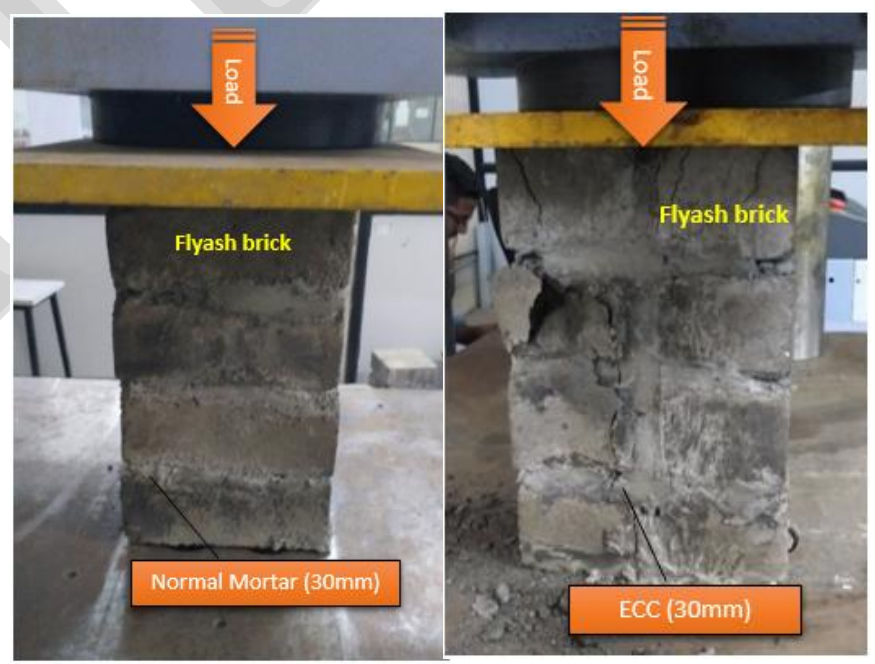

Fig10: Compressive strength test(Mortar)

Fig11: Compressive strength test(ECC) 
ECC has the capacity to strain harden after first cracking, similar to a ductile metal and demonstratea strain capacity of 300 to 500 times greater than normal concrete. Additionally, different from normal mortar, ECC exhibits self-controlled crack width under increasing load. After initial loading, a small number of cracks are formed within the material and starts spreading. This widening of crack results in micro-mechanical tailoring of ECC. Hence,only fine sand is allowed to be applied in ECC for better strain capacity and multiple cracking[23].This strain hardening capacity of ECC influence the increase in compressive strength of masonry units.

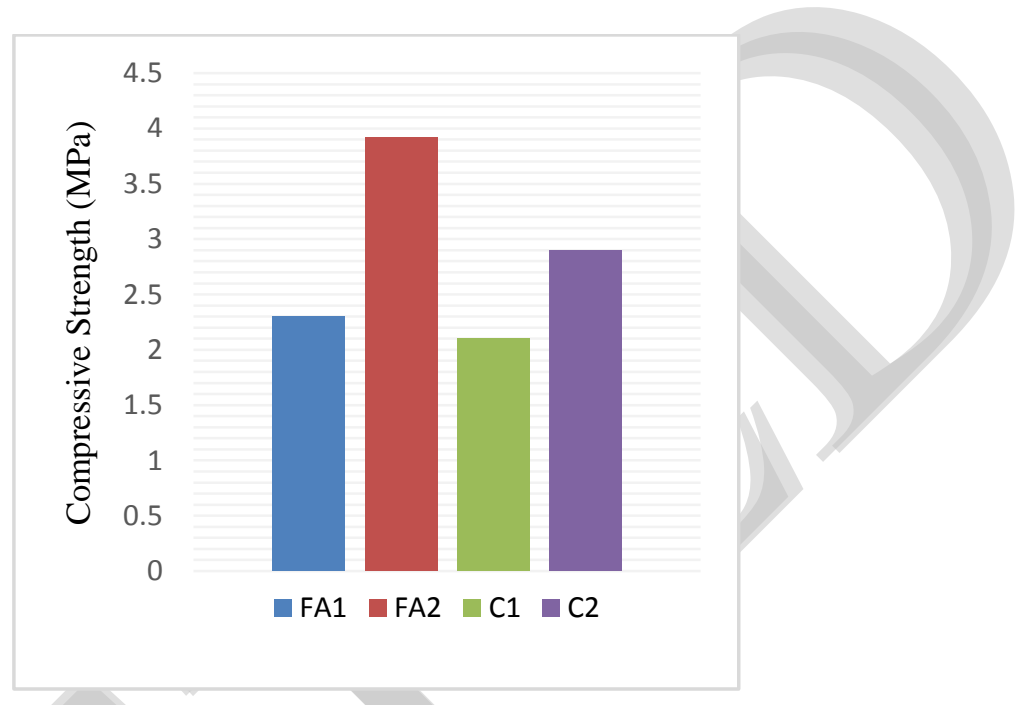

Fig12: Compressive strength of masonry prism

(Where,FA1-Flyash brick with normal mortar,FA2-Flyash brick with ECC,C1-Clay brick with normal mortar,C2-Clay brick with ECC)

\section{CONCLUSION}

Based on the experimental investigation on the behavior of cement mortar and ECC in brick masonry, the following are the conclusions can be made;

- It is noted that the mortar has a huge influence on the mechanical properties of the masonry unit.As the strength of mortar increases the compressive strength of the masonry unit also increases. The strain hardening capacity of ECC has larger influence on the increase in strength of masonry units

- The compressive strength of ECC is 55\% higher than the normal mortar.This increase in strength is due to the incorporation of steel and polypropylene fibres also resulting in microcrack behavior.

- The compressive strength and the water absorption of brick is also found to be an important factor to be considered in masonry wall construction. The strength of masonry unit increases for Flyash brick compared to clay brick.

- It is found that ECC performs with better bond strength compared to normal mortar.The shear bond strength was found to be more in case of clay brick compared to Flyash brick.Themicro- 
crack behavior is observed which is due to the bridging of cement matrix by polypropylene fibres which there by increases shear capacity.

\section{REFERENCE}

[1]Q. Zhang and V. C. Li, "Adhesive bonding of fire-resistive engineered cementitious composites ( ECC ) to steel," Constr. Build. Mater., vol. 64, pp. 431-439, 2014.

[2]J. Zhou, S. Qian, G. Ye, O. Copuroglu, K. Van Breugel, and V. C. Li, "Cement \& Concrete Composites Improved fiber distribution and mechanical properties of engineered cementitious composites by adjusting the mixing sequence," Cem. Concr. Compos., vol. 34, no. 3, pp. 342$348,2012$.

[3]V. C. Li, "Engineered Cementitious Composites for Structural applications," vol. 10, no. 2, pp. 66-69, 1983.

[4]Association of Australia, "Bond strength in masonry construction," Cem. Concr., vol. 65, no. May, pp. 1-8, 2001.

[5]S. P. SJ Lawrence, “BOND STUDIES IN MASONRY,” 10th IB² Mac, pp. 909-918, 1994.

[6]E. A. Drysdale, R.G., and Gazzola, "Influence of mortar properties on the tensile bond strength of brick masonry.," Proc. 7th Int. Brick Mason. Conf. Melbourne, Aust., pp. 927938., 1985.

[7]J. Segura, L. Pelà, and P. Roca, "Monotonic and cyclic testing of clay brick and lime mortar masonry in compression," Constr. Build. Mater., vol. 193, pp. 453-466, 2018.

[8]S. B. Singh and P. Munjal, "Bond strength and compressive stress-strain characteristics of brick masonry," J. Build. Eng., vol. 9, pp. 10-16, 2017.

[9]K. M. C. Konthesingha, C. Jayasinghe, and S. M. A. Nanayakkara, "Bond and Compressive Strength of Masonry for Locally Available Bricks," vol. XXXX, no. 04, pp. 7-13, 2007.

[10]G. Sarangapani, B. V. V. Reddy, and K. S. Jagadish, "Brick-Mortar Bond and Masonry Compressive Strength,” no. April, pp. 229-237, 2005.

[11]B. V. V. Reddy, R. Lal, and K. S. N. Rao, "Enhancing Bond Strength and Characteristics of Soil-Cement Block Masonry,” no. February, pp. 164-172, 2007.

[12]J. A. Thamboo and M. Dhanasekar, "Characterisation of thin layer polymer cement mortared concrete masonry bond," Constr. Build. Mater., vol. 82, pp. 71-80, 2015.

[13]F. M. Khalaf, "New Test for Determination of Masonry Tensile Bond Strength," no. December, pp. 725-732, 2005.

[14]I. Ronald Lumantarna, David T. Biggs, "Compressive, flexural bond and shear bond strengths of in-situ New Zealand unreinforced clay brick masonry constructed using lime 
mortar between the 1880s and 1940s,” 2012.

[15]R. Hanley, "Flexural bond strength of natural hydraulic lime mortar and clay brick," pp. 913-922, 2010.

[16]IS-1077, “Common Burnt Clay Building Bricks -Specification,” Bur. Indian Stand., 2007.

[17]BS EN772-1-2000, "Methods of tests for Masonry units.".

[18]EN1052-1, "Methods of test for Masonry," no. April, pp. 2-3, 2009.

[19]Bhaumik Merchant and Ajay Gelot, "Evaluation of Engineering Cementitious Composites (ECC) With Different Percentage of Fibers," Int. J. Eng. Res., vol. V4, no. 06, pp. 40-43, 2015.

[20]X. Shang and Z. Lu, "Impact of high temperature on the compressive strength of ECC," $A d v$. Mater. Sci. Eng., vol. 2014, 2014.

[21]AS3700:2018, "Masonry structures,” Counc. Stand. Aust., vol. 45, pp. 475-532, 2018.

[22]Y. Gregoire, "Compressive Strength of Masonry According to Eurocode 6: A Contribution to the Study of the Influence of Shape Factors," Mason. Int., vol. 6, 2005.

[23]Y. Zhu, Y. Yang, and Y. Yao, "Use of slag to improve mechanical properties of engineered cementitious composites (ECCs) with high volumes of fly ash," Constr. Build. Mater., vol. 36, pp. 1076-1081, 2012. 